\title{
Influence of Water Content on the Flow Consistency of Dredged Marine Soils
}

\author{
M. Z. Rosman ${ }^{1, *}$, S. F. S. M. Johan ${ }^{1}$, N. A. Rahman ${ }^{1}$, and C. M. Chan ${ }^{1}$ \\ ${ }^{1}$ Faculty of Engineering Technology, University Tun Hussein Onn Malaysia (UTHM), Beg Berkunci \\ 101, 86400, Parit Raja Batu Pahat Johor, Malaysia
}

\begin{abstract}
In present time, dredged marine soils (DMS) are generally considered as geo-waste in Malaysia. It is also known to contain high value of water and low shear strength. Lightly solidified soils such as soilcement slurry and flowable fill are known as controlled low strength materials (CLSM). On site, the CLSM was tested for its consistency by using an open-ended cylinder pipe. The vertical and lateral displacement from the test would determine the quality and workability of the CLSM. In this study, manufactured kaolin powder was mixed with different percentages of water. Cement was also added to compare the natural soil with solidified soil samples. There are two methods of flowability test used, namely the conventional lift method and innovative drop method. The lateral displacement or soil spread diameter values were recorded and averaged. Tests showed that the soil spread diameter corresponded almost linear with the increasing amount of water. The binder-added samples show no significant difference with non-binder sample. Also, the mixing water content and percentage of fines had influenced the soil spread diameter.
\end{abstract}

\section{Introduction}

Removal of dredged marine soils (DMS) from the sea bed is required in order to clear the passage way of ships. In Malaysia, about $300,000 \mathrm{~m}^{3}$ volumes of DMS were gathered and removed as part of maintenance dredging [1]. Soft and problematic soils like DMS posses low shear strength and high water content. Generally, the shear strength value of DMS is less than $50 \mathrm{kPa}$ [2]. With such condition, any development made on top of this unimproved soil would risk with slope failure and non-uniform settlement. In addition, transporting DMS to the designated dumping sites would cause monetary and environmental implications. With these reasons, DMS are likely to be disposed rather than to be reused.

Numerous studies show that by inducing DMS with some binders and fillers, its geotechnical properties would be improved. Other than reused as potential construction materials such as brick and cement [3,4], DMS was primarily used as reclamation fills. Binders and fillers such as cement, lime, bottom ash, fly ash and steel slag [5-8] enabled

* Corresponding author: mzawawirosman@gmail.com 
DMS to be reused as reclamation fills. Large reclamation projects in Australia, Japan and Singapore had successfully utilized DMS as backfill materials [9-11].

There are several and similar terms to describe the modified fluid-like solid used as reclamation fill. Super geomaterial (SGM) and Composite geomaterial (CGM) are both mixture of dredged soil, binder, granular materials and lightweight materials [12,13]. Self compacting material (SCM) and Controlled low strength materials (CLSM) are also related where the mixture includes less binder and granular materials [14,15]. Despite the different terms used, its function as engineered and flowable fills remained the same.

This present study relates the flow consistency of soil with water content. Increasing amount of moisture would provide more fluid-like substance, thus ease the deployment of fills.

\section{Methodology}

\subsection{Materials}

Kaolin and DMS are type of soils that contain high percentage of fines and categorized as fine-grained soils. Table 1 shows the physical properties of the related samples. In this study, manufactured kaolin FM-C powder was used to resemble DMS. Different percentages of water were added into the soil sample, denoting the phase of semi-solid to liquefied form. Manufactured cement powder was also used. The addition of cement in the soil mixture was to observe the differences of flow consistency with non-solidified soil sample. Cement with percentages of 5\% and $10 \%$ cement note the minimum and maximum of binder content in this study.

Table 1. Physical properties of related samples.

\begin{tabular}{|c|c|c|c|c|c|c|c|}
\hline Samples & Kaolin & $\begin{array}{c}\text { Tokyo } \\
\text { Bay A* }\end{array}$ & $\begin{array}{c}\text { Tokyo } \\
\text { Bay B* }\end{array}$ & Kobe* & Okhots** & $\begin{array}{c}\text { Kasaoka } \\
\text { Clay* }\end{array}$ & $\begin{array}{c}\text { Kuni- } \\
\text { bond* }\end{array}$ \\
\hline $\mathrm{W}_{\mathrm{L}}[\%]$ & 79.6 & 114.7 & 112.4 & 108.2 & 85.6 & 55.4 & 133.1 \\
\hline $\mathrm{WC}_{\mathrm{M}}[\%]$ & $\begin{array}{c}60,80,100, \\
120,160\end{array}$ & 285 & 285 & 285 & 285 & 285 & 285 \\
\hline$\rho_{\mathrm{s}}\left[\mathrm{g} / \mathrm{cm}^{3}\right]$ & 2.56 & 2.62 & 2.70 & 2.64 & 2.56 & 2.71 & 2.70 \\
\hline Fines $[\%]$ & 57 & 98 & 92 & 100 & 94 & 93 & 94 \\
\hline
\end{tabular}

*: Samples referred to [12]

\subsection{Aspect ratio}

The test procedure was based on standard [16], where an open-ended cylinder was used to fill the soil mixtures. Various size and dimension of the ring pipe cylinder used in other studies were stated in Table 2. Diameter to height aspect ratio of the cylinder was used to compare the present and standard cylinder. The present ring pipe cylinder used in this study is $52 \mathrm{~mm}$ of diameter and $30 \mathrm{~mm}$ of height. As calculated, the ratio of the present cylinder size was less than the standard cylinder size $(0.00037<0.51)$. Hence, the dimension of the ring pipe cylinder used in present study is permissible. 
Table 2. Variation in dimension of ring cylinder used.

\begin{tabular}{|c|c|c|c|}
\hline No. & Diameter x Height & Aspect Ratio & References \\
\hline 1. & $50 \mathrm{~mm} \times 100 \mathrm{~mm}$ & 0.50 & {$[12]$} \\
\hline 2. & $75 \mathrm{~mm} \times 150 \mathrm{~mm}$ & 0.50 & {$[13]$} \\
\hline 3. & $76 \mathrm{~mm} \times 150 \mathrm{~mm}$ & 0.51 & {$[16]$} \\
\hline 4. & $38 \mathrm{~mm} \times 76 \mathrm{~mm}$ & 0.50 & {$[17]$} \\
\hline
\end{tabular}

\subsection{Flowability test methods.}

Batches of soil mixture were mixed with $0.75 \mathrm{~W}_{\mathrm{L}}, 1.00 \mathrm{~W}_{\mathrm{L}}, 1.25 \mathrm{~W}_{\mathrm{L}}, 1.50 \mathrm{~W}_{\mathrm{L}}, 1.75 \mathrm{~W}_{\mathrm{L}}$ and $2.00 \mathrm{~W}_{\mathrm{L}}$ of its liquid limit $\left(\mathrm{W}_{\mathrm{L}}\right)$. The variance of water content was intended to examine the behavior of soil that undergoes such levels of saturation. Another series of soil mixture incorporated with $5 \%$ and $10 \%$ of cement were also mixed with the same pre-determined moisture content. The flowability test was then prepared in two methods, namely the conventional lift method and innovative drop method.

Lift method consist of filling the soil mixture inside a ring cylinder. As the ring cylinder was slowly lifted up, the soil samples would then segregated by its own weight and form lateral displacement of soil spread. Note that before filling, the ring has been lubricated with oil or water. Due to the cohesive nature of fine grained soil, most of the soil sample adhered to the wall of the cylinder. Therefore, an innovative method that allow the soil samples to be drop at raised level was conducted. Similarly, the soil sample was filled inside the ring cylinder on a base platform. By removing the platform, the soil sample would drop at the height of $175 \mathrm{~mm}$ as refer to Figure. 1. It is comparable with the lift method since the soil sample for fall method segregated by gravity. Only the average value of soil spread diameter was measured and recorded.
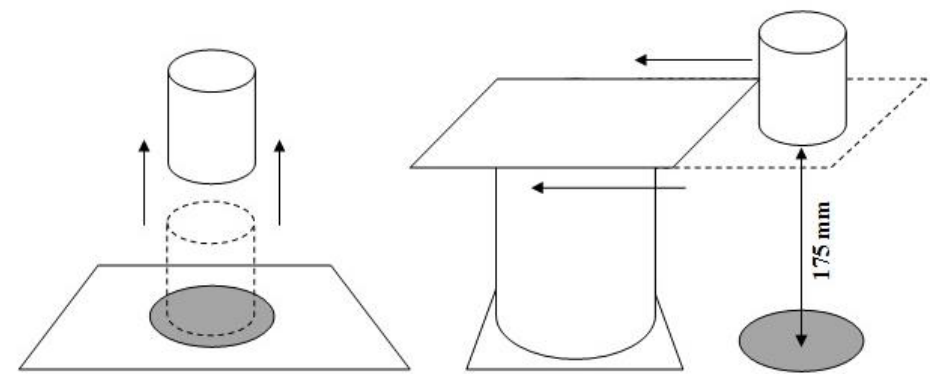

Fig. 1. Schematic diagrams of lift method $[l e f t]$ and drop method $[$ right $]$.

\section{Results and Discussion}

\subsection{Influence of water content and binder.}

The average values of soil spread diameter $\left(\mathrm{S}_{\mathrm{D}}\right)$ were plotted against water content $(\mathrm{WC})$ as shown in Figure 2. Clearly the soil spread diameter was influenced by the water content. The soil spread diameter increased with the increasing amount of moisture. The flowability of soil and binder mixture was also made in order to examine whether distinct values of spread diameter occurred. With the addition of cement, less spread diameter can be observed with the increasing dosage of $5 \%$ and $10 \%$. However, there were no such significant differences. It is likely that the cemented soil samples reacted with water which had caused cement hydration. 

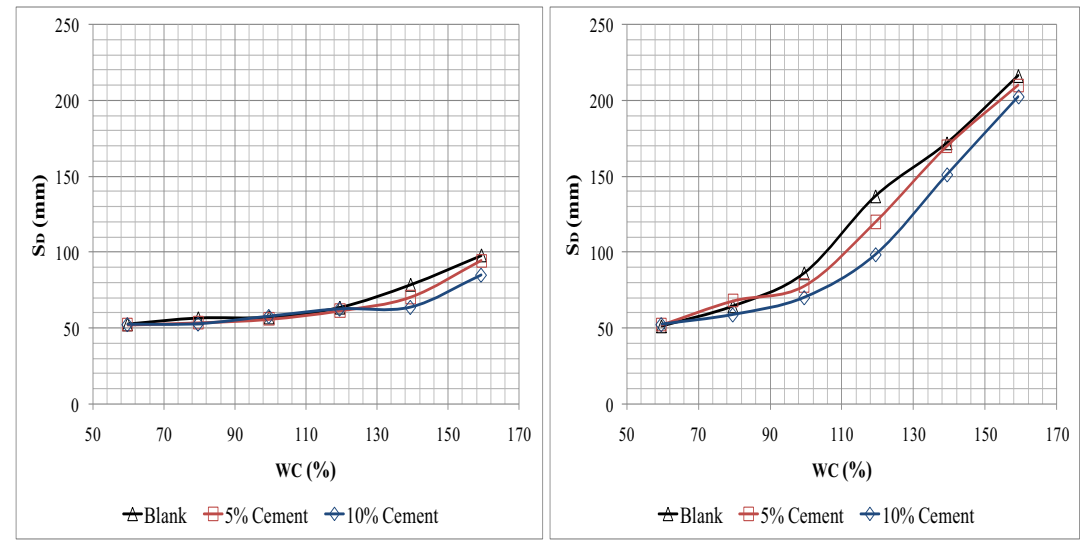

Fig. 2. Flowability test values for lift method [left $]$ and drop method $[$ right $]$.

\subsection{Influence of method.}

Flowability by innovative fall method resulted with larger spread diameter than the conventional lift method. With more water content, the soil matrix tends to loosen and break apart. At raised level, samples by fall method were dropped by its gravitational weight. Both of the reasons contributed to the large displacement. Even so, both methods show increasing trend line in spread diameter against water content graphs.

\subsection{Influence of ring cylinder.}

Comparison values of data between kaolin and samples from [12] were tabulated in Table 3. The index values of mixing water content and liquid limit $\left[\mathrm{WC}_{\mathrm{M}} / \mathrm{W}_{\mathrm{L}}\right]$ of kaolin were predetermined. Apparently, the index values of spread diameter and initial diameter $\left[\mathrm{S}_{\mathrm{D}} / \mathrm{D}\right]$ were less than the others. Based from the dimension of the ring cylinders used, only the ring height for kaolin differs from the others. Despite the difference, the dimension of ring cylinders was not the main reason for the different values. Even if the ring height for kaolin sample is the same, the $S_{D} / D$ value still less than the others ranged values. Illustrated in Fig.3, the normalized graph of $\mathrm{S}_{\mathrm{D}} / \mathrm{D}$ and $\mathrm{WC}_{\mathrm{M}} / \mathrm{W}_{\mathrm{L}}$ shows the distinct values of kaolin and other soil samples. According to Table 1, the mixing water content $\left[\mathrm{WC}_{\mathrm{M}}\right]$ and percentages of fines [\%] were less than the other samples. Obviously, higher water content and finer samples would produce large $\mathrm{S}_{\mathrm{D}}$ values.

Table 3. Index values of kaolin and referenced samples.

\begin{tabular}{|c|c|c|c|c|c|c|c|}
\hline Samples & Kaolin & $\begin{array}{c}\text { Tokyo } \\
\text { Bay A* }\end{array}$ & $\begin{array}{c}\text { Tokyo } \\
\text { Bay B* }\end{array}$ & Kobe $^{*}$ & Okhotsk** $^{*}$ & $\begin{array}{c}\text { Kasaoka } \\
\text { Clay* }\end{array}$ & $\begin{array}{c}\text { Kuni- } \\
\text { bond* }\end{array}$ \\
\hline $\mathrm{WC}_{\mathrm{M}} / \mathrm{W}_{\mathrm{L}}$ & $\begin{array}{c}0.75,1.00,1.25, \\
1.50,1.75,2.00\end{array}$ & 2.50 & 2.50 & 2.60 & 3.30 & 5.10 & 2.10 \\
\hline $\mathrm{H}[\mathrm{mm}]$ & 30 & 100 & 100 & 100 & 100 & 100 & 100 \\
\hline $\mathrm{D}[\mathrm{mm}]$ & 52 & 50 & 50 & 50 & 50 & 50 & 50 \\
\hline $\mathrm{S}_{\mathrm{D}}[\mathrm{mm}]$ & $\begin{array}{c}53,56,57,64,79, \\
98\end{array}$ & 475 & 580 & 490 & 640 & 660 & 570 \\
\hline $\mathrm{S}_{\mathrm{D}} / \mathrm{D}$ & $\begin{array}{c}1.02,1.08, \\
1.10,1.23, \\
1.52,1.88^{* *}\end{array}$ & 9.50 & 11.60 & 9.80 & 12.80 & 13.20 & 11.40 \\
\hline
\end{tabular}

*: Samples referred to [12] **: $\mathrm{S}_{\mathrm{D}}$ values for lift method 


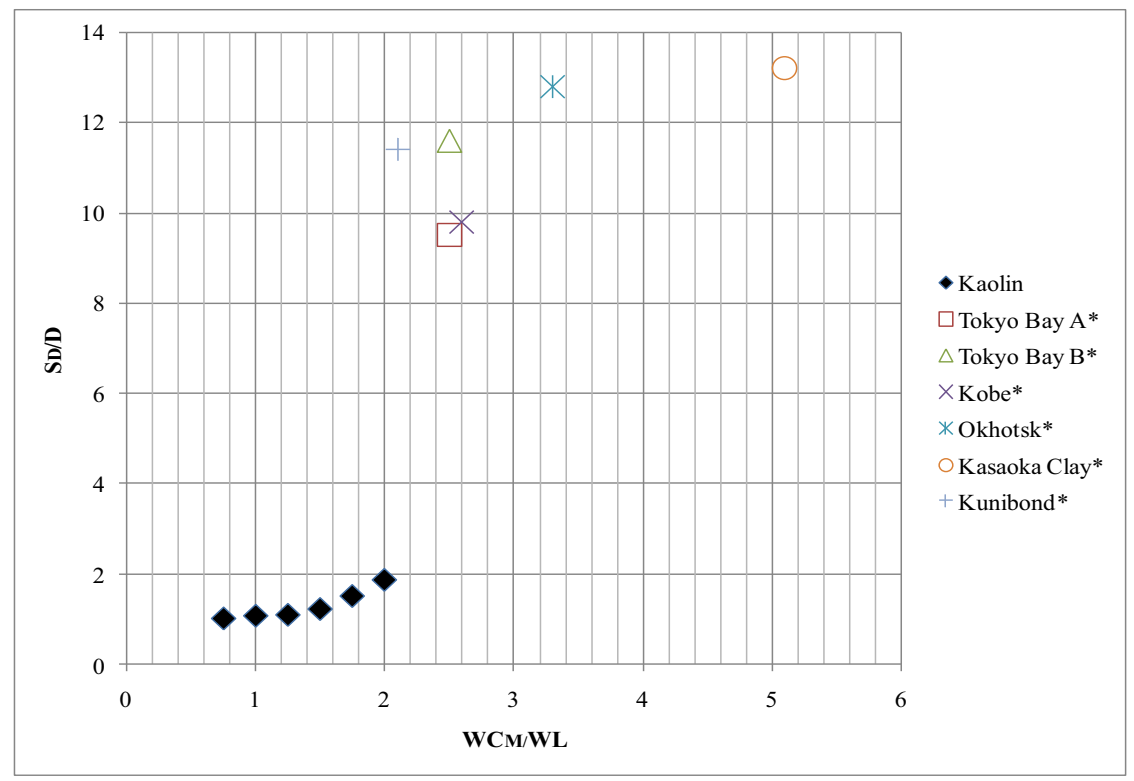

Fig. 3. Normalized results between $S_{D} / D$ and $\mathrm{WC}_{M} / W_{L}$.

\section{Conclusion}

In this study, series of soil mixture with different water percentages and binder contents were conducted. The purpose of this study is to examine the influence of moisture towards the soil samples regardless whether non-solidified or solidified. The findings are summarized as follows;

- Higher water content would resulted higher spread diameter

- By adding minimum and maximum dosage of cement namely $5 \%$ and $10 \%$, it had affected the spread diameter accordingly. It is highly due to hydration effect between cement and water.

- Non-solidified and solidified samples do not have that significant difference of spread diameter and water content relationship.

- Despite the test methods used, both methods shows similar trend line of spread diameter and water content relationship.

- Mixing water content and percentage of fines had affected the soil spread diameter.

\section{References}

1. W.S.W. Salim, S.F. Sadikon, S.M. Salleh, N.A.M. Noor, M.F. Arshad, N. Wahid, IEEE Symposium on Business, Engineering and Industrial Applications, 23, 509 (2012)

2. C.F. Chiu, W. Zhu, C.L. Zhang, Eng. Geol., 103, 1 (2009)

3. W.S.W. Salim, N.A.M. Noor, M.F. Arshad, N. Wahid, S.M. Salleh, Proceeding of the $2^{\text {nd }}$ International Conference on Biotechnology and Environment Management (2012)

4. T.A. Dang, S. Kamali Bernard, W.A. Prince, Constr. Build. Mater., 41, 602 (2013)

5. A. Azhar, C.M. Chan, A.T.A. Karim, Electronic Journal of Geotechnical Engineering, 19, $8797(2014)$ 
6. C.M. Chan, T. Mizutani, Y. Kikuchi, International Journal of Civil and Structural Engineering, 2, 270 (2011)

7. H.W. Xiao, F.H. Lee, International Journal of Civil, Environmental, Structural, Construction and Architectural Engineering, 2, 144 (2008)

8. G. Rajasekaran, S.N. Rao, Ocean Eng., 29, 545 (2002)

9. D. Ganesalingam, J. Ameratunga, G. Schweitzer, Proceeding of the $18^{\text {th }}$ International Conference on Soil Mechanics and Geotechnical Engineering (2013)

10. Y. Watabe, T. Noguchi, Proceeding of Indian Geotechnical Conference (2011)

11. A. Arulrajah, M.W. Bo, H. Nikraz, Proceeding of the $6^{\text {th }}$ International Conference on Case Histories in Geotechnical Engineering Paper (2015)

12. S. Kataoka, T. Horita, M. Tanaka, R. Tomita, M. Nakajima, Proceeding of the $18^{\text {th }}$ International Conference on Soil Mechanics and Geotechnical Engineering (2013)

13. Y.T Kim, C. Lee, H.I. Park, Mar. Georesour. Geotec., 29, 1 (2011)

14. J. Kanadasan, A.F.A. Fauzi, H.A. Razak, P. Selliah, V. Subramaniam, S. Yusoff, Materials, 8, 6518 (2015)

15. K.H. Lee, J.D. Kim, J. Civ. Eng., 17, 674 (2013)

16. ASTM D6103-04, Standard Test Method for Flow Consistency of Controlled Low Strength Material (West Conshohocken 2004)

17. C.M. Chan, M.N.M. Yusof, Modern Applied Science, 9, 13 (2015). 